\title{
Issues on the Use of Online Learning: An Exploratory Study Among University Students During the COVID-19 Pandemic
}

\author{
Azleen Ilias ${ }^{1, *}$, Nasrudin Baidi ${ }^{2}$, Erlane K. Ghani ${ }^{3}$, Fazlida Mohd Razali ${ }^{4}$ \\ ${ }^{1}$ Department of Accounting and Finance, College of Business Management and Accounting (COBA), \\ Universiti Tenaga Nasional (UNITEN), Muadzam, Malaysia \\ ${ }^{2}$ Department of Business and Management, College of Business Management and Accounting (COBA), \\ Universiti Tenaga Nasional (UNITEN), Muadzam, Malaysia \\ ${ }^{3}$ Faculty of Accountancy, Universiti Teknologi MARA Selangor, Puncak Alam, Malaysia \\ ${ }^{4}$ Department of Accounting and Finance, Faculty of Business Management \& Professional Studies (FBMP), \\ Management and Science University (MSU), Shah Alam, Malaysia
}

Received June 16, 2020; Revised August 8, 2020; Accepted August 28, 2020

\section{Cite This Paper in the following Citation Styles}

(a): [1] Azleen Ilias, Nasrudin Baidi, Erlane K.Ghani, Fazlida Mohd Razali, "Issues on the Use of Online Learning: An Exploratory Study Among University Students During the COVID-19 Pandemic," Universal Journal of Educational Research, Vol. 8, No. 11, pp. 5092-5105, 2020. DOI: 10.13189/ujer.2020.081109.

(b): Azleen Ilias, Nasrudin Baidi, Erlane K.Ghani, Fazlida Mohd Razali (2020). Issues on the Use of Online Learning: An Exploratory Study Among University Students During the COVID-19 Pandemic. Universal Journal of Educational Research, 8(11), 5092-5105. DOI: 10.13189/ujer.2020.081109.

Copyright $(\mathrm{O} 2020$ by authors, all rights reserved. Authors agree that this article remains permanently open access under the terms of the Creative Commons Attribution License 4.0 International License

\begin{abstract}
Online learning has become important to most students and lecturers in this academic era due to the COVID-19 Pandemic. This study attempted to investigate issues pertaining to online learning among university students in Malaysia during this pandemic. The online interview technique used various online platforms involving 147 students from 16 universities in Malaysia. Data from the interview were analysed using ATLASti. Findings indicated that there are seven challenges that might limit the intention to use online learning among students. The challenges outlined are the administrator's assessment, communication issues that limit social interaction during online learning sessions, technical issues as well as an unstable Internet connection and insufficient data capacity. This study could contribute to the existing corpus of knowledge that could help universities to strategize the future implementation of online learning and minimize the challenges. This could improve the intention and preferences to use online learning for future implementation.
\end{abstract}

Keywords COVID-19, Online Learning, Malaysia, ATLASti, Challenges

\section{Introduction}

COVID-19 and its rapid escalation into a global pandemic have had a significant impact on the global economic outlook. Most governments around the world have begun to practice initiatives suggested by the World Health Organization (WHO), which is a response to increase the level of preparedness and alertness in managing COVID-19 cases. The WHO also mentioned that Coronaviruses are a large family of viruses that cause illnesses in animals and humans. In humans, several Coronaviruses are known to cause respiratory infections ranging from the common cold to more severe infections. COVID-19 is not very different from Severe Acute Respiratory Syndrome (SARS), but its clinical features suggest it is less dangerous than the Middle East Respiratory Syndrome (MERS) [1]. The WHO has encouraged everyone to stay at home, go into self-isolation and keep a distance of at least 1 meter ( 3 feet) apart from another individual as COVID-19 spreads via small droplets 
exiting from the nose or mouth when an infected person coughs or exhales. This initiative has been implemented by several countries, such as Indonesia, Singapore, Thailand. Malaysia began with the 2020 Movement Control Order (MCO) that started on 18 March 2020.

Hence, due to the implementation of the MCO, Malaysia's education system has gone online, with most private and public universities following suit. This is important for both students and lecturers when preparing for continued online learning in the future. Online learning during the MCO provides numerous benefits, one of which is developing new skillsets related to online learning [2]. During the MCO, both lecturers and students face several challenges in ensuring continuity in the online learning process [3]. The top three challenges are educators' experience and skills in using the online system and online applications, the infrastructure's state of readiness (internet connectivity, bandwidth and devices) and an evolving mindset (involving educators and students) [2], as well as the readiness, skills, internet connectivity and devices [4]. However, according to Universiti Kebangsaan Malaysia's Centre for Education and Community Well-Being, Malaysia is not fully ready to embrace online teaching and learning as internet services in rural areas are slow and unstable [3]. Therefore, this study focuses on students' opinions that could provide a better understanding of how students perceive online learning. Data from students was obtained via open-ended questions. This method is consistent with previous studies that suggested that open-ended questions provide information about an individual's opinion, which cannot be obtained through multiple choice questions [5].

The findings of this study provide an understanding of the use of online learning among students during the COVID-19 Pandemic as well as ideas for a support system in the field of education in universities, agencies, and relevant ministries. Section 2 presents the literature review, followed by Section 3, which concerns the research methodology, and then the results and discussions in Section 4. The final section, Section 5, concludes this study.

\section{Literature Review}

\section{Online Learning}

Online learning, or e-learning, provides a virtual learning environment that engages students in various activities involving a multitude of subjects through the audio-visual platform [6]. Online learning is used for delivering information, while the database system is used for managing, communicating content, interacting or facilitating teaching and learning activities [8]. Several benefits of using online learning were found, such as flexibility in scheduling and lower costs compared to offline learning [9], increasing students' sociability, confidence and participatory qualities [10] and improving the quality of projects and information sharing [8].

\section{Importance of Online Learning}

The COVID-19 Pandemic has created a need to engage in online learning with the importance lying in its adoption by the majority in the education sector, particularly universities. Online learning is essential for the teaching and learning process, besides face-to-face and other traditional methods [11]. There are several reasons for adopting online learning, as mentioned in previous studies. Studies have noted that online learning operates using the Internet and there is no limit to the number of participants [12]. Moreover, online learning improves student accessibility and encourages a higher rate of completion $[13,14]$. In addition, the purpose of adopting online learning is to complement traditional methods of manual presentation and face-to-face interaction, which is useful to both learners and teachers [9].

\section{Online Learning in Malaysia}

The COVID-19 Pandemic has strongly encouraged the adoption of online learning on a worldwide scale, including in Malaysia. Numerous studies on online learning in Malaysia have touched on its use by both students and teachers. In general, studies have discussed the implementation of online learning by 18 public universities [15], investigated the usefulness and effectiveness of online learning in Universiti Teknologi Malaysia (UTM) [6], investigated students' online discussion strategies pertaining to project work at the Technical University of Malaysia [9], reasons for getting involved in online learning at Universiti Kebangsaan Malaysia (UKM) [11] and factors that influence students' acceptance of online learning in teaching institutions in Malaysia [16].

\section{Factors that Influence the Intention to Adopt Online Learning}

There is a need to identify factors that influence the use of online learning. This is because most previous studies were concerned with factors such as gender, age, ethnicity, type of learning institution, the ability and confidence in online learning technology, learning enjoyment, the number of online courses completed or dropped, the likelihood of taking future online courses as well as cultural background, disability, or other personal characteristics [17]. Other related factors are the communication process, course management issues, and course websites or course management systems used [13, 18]. Studies also confirmed that students' perception of task value and self-efficacy, social ability, quality of system, and multimedia instruction are some of the 
important factors [19.20].

Meanwhile, studies have also suggested that the content of e-learning, self-efficacy and perceived usefulness have an effect on students' intention to engage in online learning [6]. Perceived ease-of-use, perceived usefulness as well as individual and social factors are four variables that directly impact the adoption of online learning [16]. In addition, perceived usefulness, perceived ease-of-use and online learning behavioural attitude do positively affect users' behavioural intention, which then indirectly affects users' satisfaction [21]. A study found six factors that influence students' acceptance of online learning, but the two main factors were the perception about usability, ease-of-use, system quality and information quality as well as lecturer's characteristics and technical support [7]. This study cited five factors, which were students, instructors, design, course and technical elements that influence students' satisfaction in using online learning. Other factors such as technological, task, individual aspects as well as social, and organisational factors that affect online learning in higher education institutions in Yemen [22]. Conversely, personal factors, such as the perception about the interaction, cognitive absorption, escape mechanism and cognitive age play a vital role in determining the use of technology [10].

\section{Challenges of Online Learning}

Previous studies have discussed numerous challenges faced by both students and teachers. Several challenges faced by students, in the form of administrative issues, social interaction, academic and technical skills, motivation, time, limited access to resources, and technical difficulties were discovered [17]. Students faced several challenges when using online learning, including the lack of online student discipline, lack of acceptance by the faculty, and high costs associated with online development and delivery $[13,23]$. These challenges are similar to studies such as unfamiliar roles and responsibilities, delay in feedback from instructors, limited technical assistance, high degree of dependence on technology as well as low student performance and satisfaction $[24,25]$. Challenges can also arise due to a lack of motivation as well as a sense of alienation and isolation as students feel that they are an online component [26]. Students found it less interesting than other forms of learning, not student-friendly, and not sufficiently interactive to make students feel more connected to the faculty and friends through such platforms as Facebook, WhatsApp, WeChat, and email [7, 27]. Meanwhile, several challenges, such as students' attitude, human resources, time constrain, lecturer's self-efficacy and technical problems have also been raised [12].

\section{Models Used to Examine the Intention of Online Learning}

There are models applied in online learning studies that focus on the intention to adopt it and the satisfaction that accrues from using it. DeLone and Mclean's Information System's Success Model has been adopted to measure the system, information, service qualities, facilitating conditions, and individual technical skills that impact online learning $[22,28]$. There are other models that can be used for assessing online learning among users, such as the E-learning Maturity Model [29], E-learning's Critical Success Factors Model [9], and the Technology Acceptance Model [30]. The extended Unified Theory of Acceptance and Use of Technology 2 (UTAUT2) theory is used to illustrate predictors such as expected performance, hedonic motivation, habit and trust are significant when predicting behavioural intention. In addition, several studies have used an extension of the Technology Acceptance Model (TAM) for measuring students' perspective ([16]; and the IS Success Model [7] for measuring lack of security and privacy [31], performance expectancy, hedonic motivation, habit and trust [32], course design and previous experiences [33] technical support [34], informal social circle, external social circle, personal innovativeness, and self-efficacy [16], perception of the interaction, cognitive absorption, escape mechanism, cognitive age, culture, surrounding conditions and the social network [10]. Besides these models, there are also concepts that are used to understand the challenges of online learning [17], such as administrative issues, social interaction, academic skills, technical skills, learner motivation, time and support for studies, cost and access to the Internet, and technical problems.

\section{Research Methodology}

\section{Samples}

Table 1. List of universities and number of students

\begin{tabular}{|c|c|c|c|}
\hline No & University & $\begin{array}{c}\text { Number of } \\
\text { Students }\end{array}$ & $\begin{array}{c}\text { Respondents } \\
\text { Identification (ID) }\end{array}$ \\
\hline 1. & INTI & 1 & I1 \\
\hline 2. & MSU & 22 & M1-M22 \\
\hline 3. & POLITECHNIC & 2 & $\mathrm{P} 1, \mathrm{P} 2$ \\
\hline 4. & UCSF & 2 & $\mathrm{UC} 1, \mathrm{UC} 2$ \\
\hline 5. & UIA & 1 & U11 \\
\hline 6. & UITM & 32 & UIT1-UIT32 \\
\hline 7. & $\mathrm{UM}$ & 11 & UM1-UM9, UM11 \\
\hline 8. & UMS & 27 & UMS1-UMS27 \\
\hline 9. & UNITEN & 21 & UN1-UN21 \\
\hline 10. & UNIMAS & 1 & UNI1 \\
\hline 11. & UNISEL & 1 & UNIS1 \\
\hline 12. & UPM & 5 & UP1-UP5 \\
\hline 13. & USM & 9 & US1-US9 \\
\hline 14. & UTM & 2 & UT1-UT2 \\
\hline 15. & UUM & 6 & UU1-UU6 \\
\hline 16. & UNISZA & 4 & UZ1-UZ4 \\
\hline 17. & & 147 & \\
\hline
\end{tabular}


Respondents in this study comprised 147 students from 16 public and private universities in Malaysia who were interested in participating in this study during the earlier part of the COVID-19 Pandemic. Respondents in this study were randomly selected by lecturers who invited students who were interested in this study. Each student was given an ID for easier recognition and processing, as shown in Table 1 .

\section{Data Collection and Analysis}

This study was conducted during the COVID-19 Pandemic, which was from $1^{\text {st }}$ April 2020 to $20^{\text {th }}$ April 2020 , by employing the online interview method. Online invitations were sent to representatives from each university informing them about the aim of this study and for their valued participation. Conversations were also held through various online platforms, such as WhatsApp, Google email, Facebook, LinkedIn, and padlet. These platforms were used since face-to-face meetings were not allowed during the MCO and strict social distancing was also required. Moreover, universities were also closed during the MCO. Each opinion on the use of online learning was recorded using several methods, such as the notebook, Excel format or a photoshoot/screenshot of a conversation. Each statement reflecting an opinion was prepared in Microsoft Word format and transferred to ATLASti for analysis based on codes, as shown in Figure 1 .

The coding process was based on eight factors that were identified according to [29]. Then, eight themes were developed from the coding trend obtained from 147 students. Below is the picture of Atlasti and an example of the Excel format used for analysing data in the code manager (Figure 2, 3 and 4).

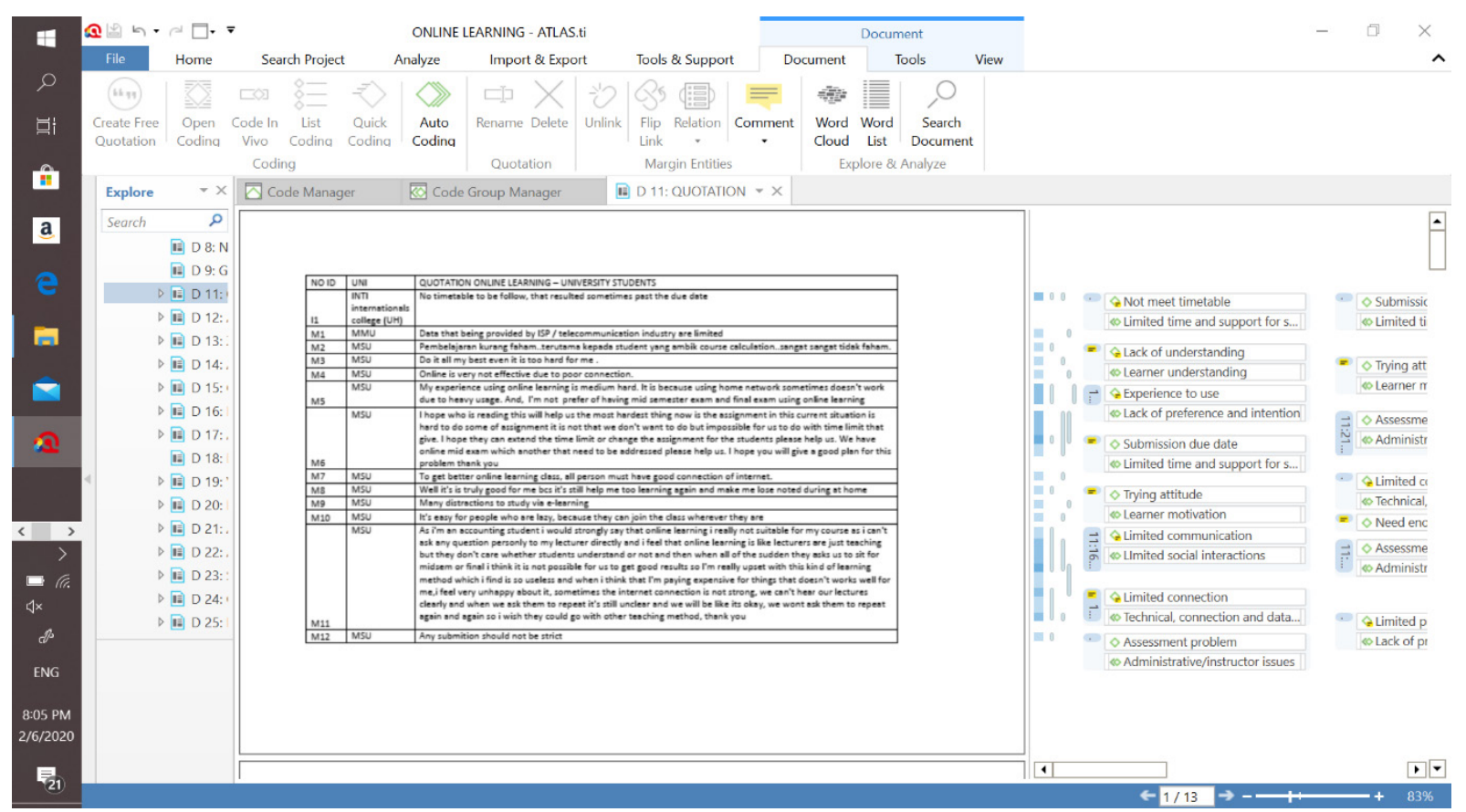

Figure 1. Example of ATLASti coding process 


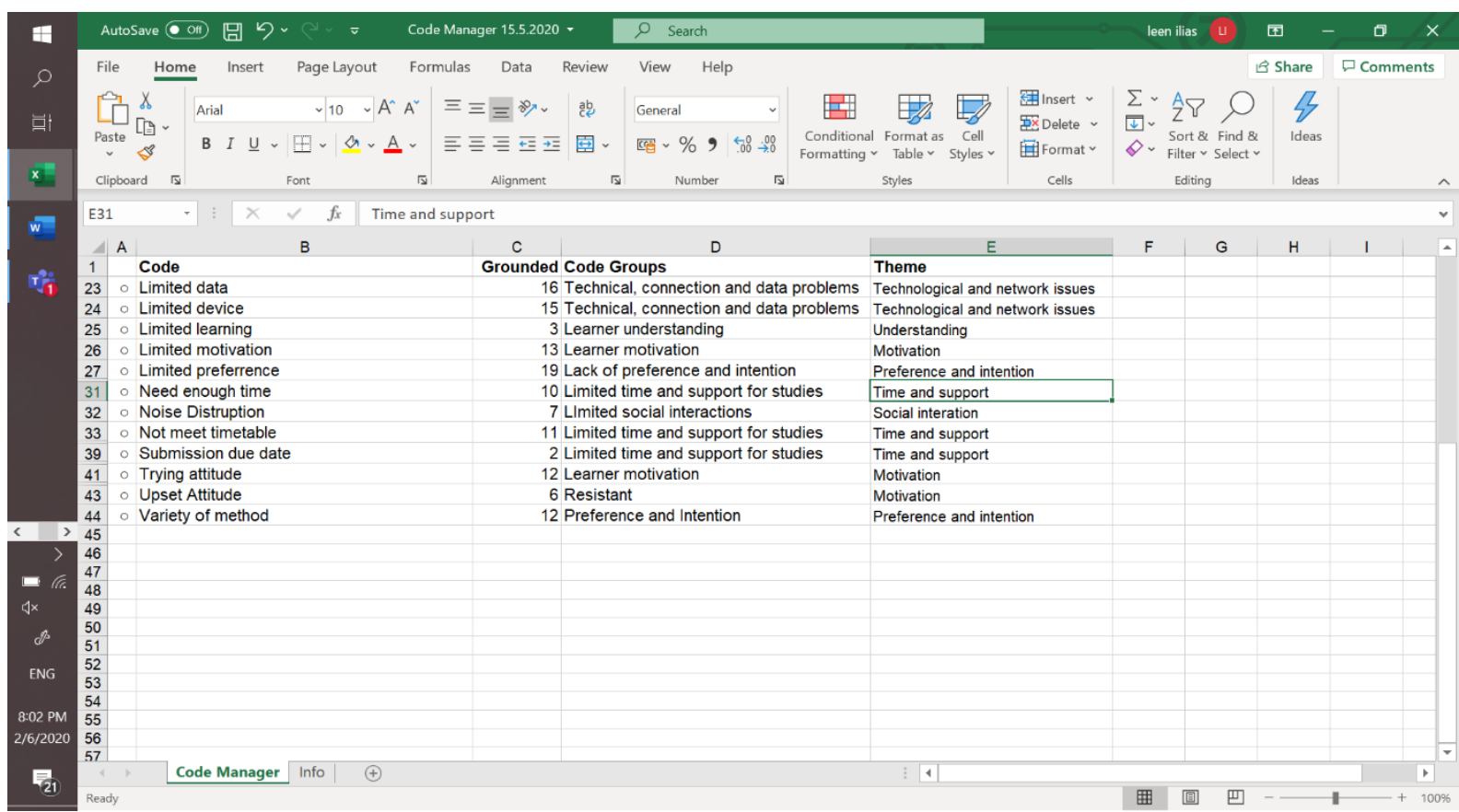

Figure 2. Example of ATLASti code group or theme

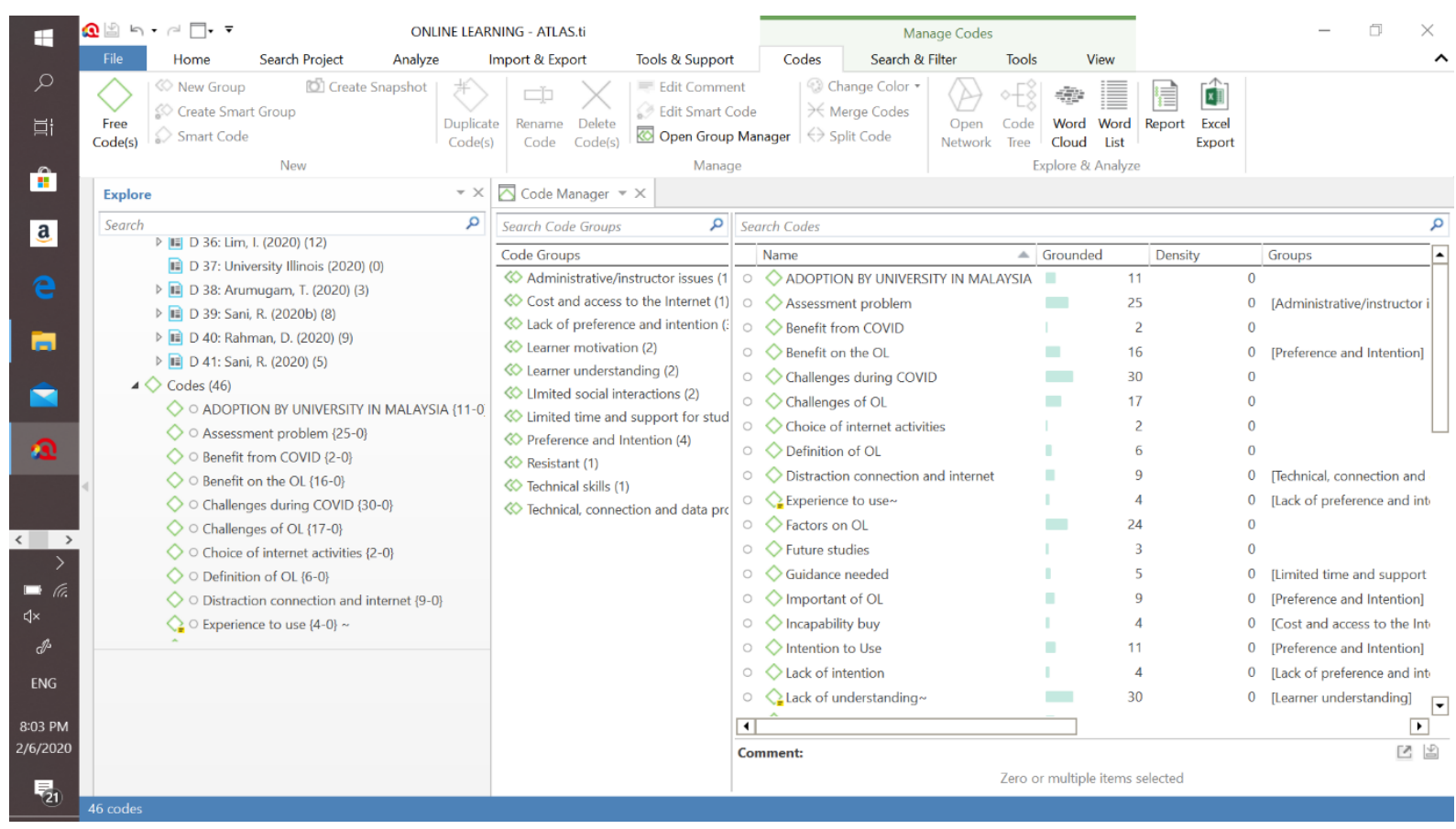

Figure 3. Example of ATLASti code group or theme 


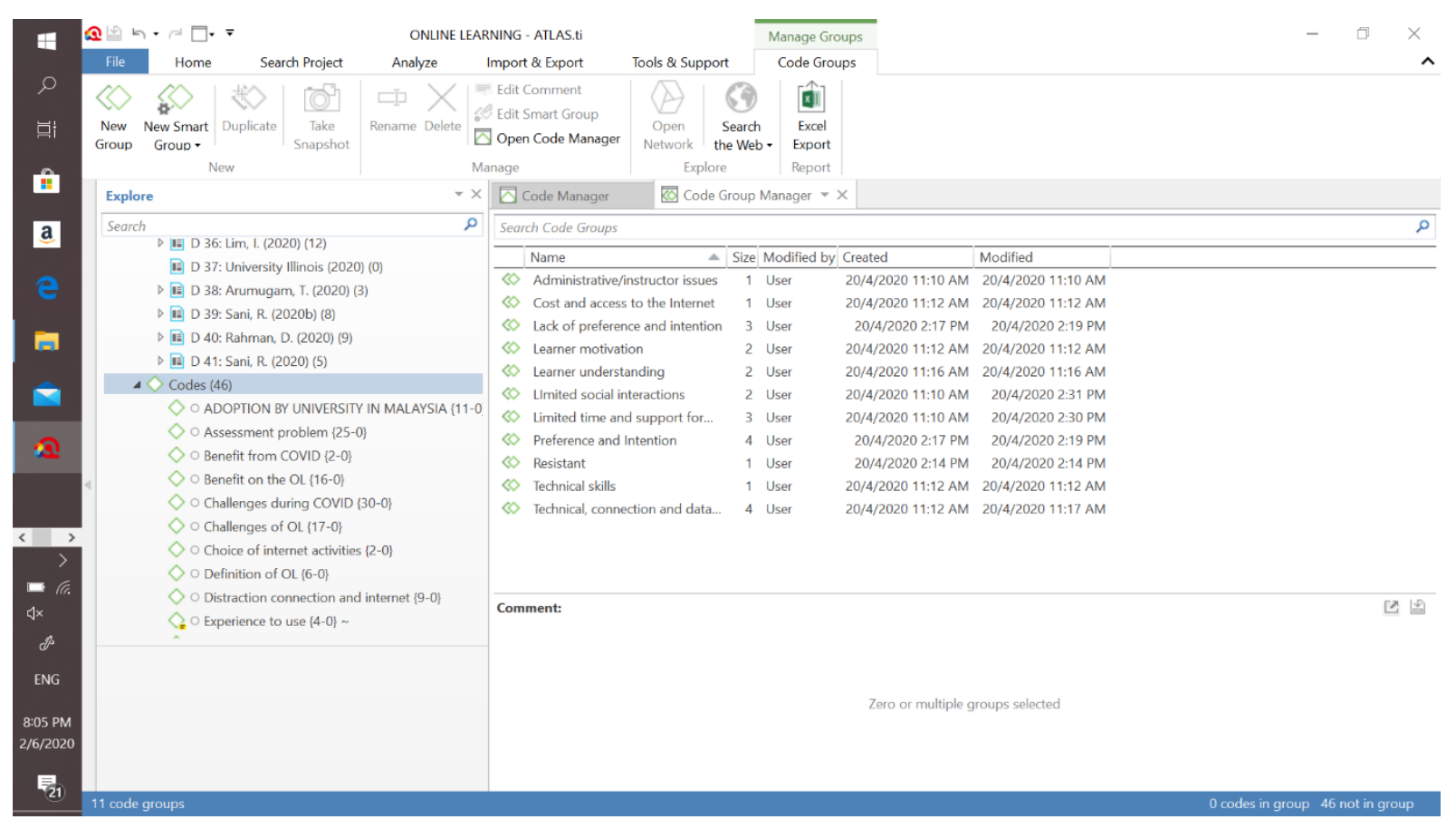

Figure 4. Example of ATLASti code group or theme

Table 2. Experience and Intention to Use the Online Learning

\begin{tabular}{cccc}
\hline Experience on the online learning & Frequency & Intention to use any type of online learning & Frequency \\
\hline Google classroom & 46 & Google classroom & 18 \\
\hline Google meet & 16 & Google meet & 14 \\
\hline Google hangout & 33 & Google hangout & 7 \\
\hline Zoom & 98 & Zoom & 44 \\
\hline Webex & 3 & Webex & 7 \\
\hline SKYPE & 15 & SKYPE & 6 \\
\hline Microsoft Team & 2 & Microsoft Team & 3 \\
\hline E-learning from university & 73 & E-learning from university & 29 \\
\hline Youtube & 6 & Youtube & 3 \\
\hline Whatsapp & 9 & Whatsapp & 12 \\
\hline Webinar & 1 & Screeccast-O-Matic & 1 \\
\hline Padlet & 5 & Padlet & 1 \\
\hline Google drive & 2 & Google drive & 1 \\
\hline Kahoot & 4 & Kahoot & 3 \\
\hline Facebook & 3 & Facebook \\
\hline $\begin{array}{l}\text { Others such as bigblue button, discord, edmodo, } \\
\text { evernote, pre-recorded video, cidos and flipgrid }\end{array}$ & 17 & $\begin{array}{l}\text { Others such as bigblue button, discord, edmodo, } \\
\text { evernote, pre-recorded video, cidos and flipgrid }\end{array}$ & 14 \\
\hline
\end{tabular}

\section{Findings and Discussion}

\section{Experience of Online Learning Prior and During the COVID-19 Pandemic}

Based on the interview, 98 respondents had experience in using Zoom, 73 respondents had used some type of e-learning in their universities, 46 had used Google classroom and 33 had used Google hangout (Table 2).
Based on the interview data, most respondents had limited experience in using an online learning medium, such as Webex, Webinar, Padlet, Kahoot, Facebook or other mediums. However, data had changed due to the intention to use any type of medium at the end of the interview. Respondents who intended to use online learning had shown limited interest due to their experience. Most probably, their intention was based on issues resulting from their experience, which is discussed in the next section. 


\section{Issues about Online Learning}

\section{Administrator Issues}

One of the issues is the way a lecturer, who acts as an administrator, makes assessments of students during the COVID-19 Pandemic. The assessment was carried out by the lecturer and each student faced different problems during the assessment. This observation was evident when 12 students were assessed during this pandemic, as mentioned in the excerpts below.

The hardest thing now is the difficulty in doing the assignment considering the current situation. It is not that we don't want to do it, but it is almost impossible for us to do it given the time constraint (M6).

I find it a drag thing - to do every assessment by the lecturer, especially when there is so much work (UMS2).

Once, I was doing my quiz online and suddenly I could not access the internet. Got stuck and in the end, I did not manage to finish my quiz as the time was up already. In addition, I once wanted to upload and send my assignment, but the coverage was not good. It really took some time to upload and sometimes it failed and that frustrated me (UIT26).

I could not get to access my Moodle, especially during the critical moment, i.e. when I needed to answer my midterm exam and quizzes as the Moodle server broke down (UN3).

Based on the above issues, insufficient time for administrators to carry out assessments is one of the challenges faced during online learning. Lecturers should show some concern since they also act as administrators during online classes. Lecturers need to recognise students' needs, the time allotted, the delivery method used and accessibility to the internet prior to conducting any assessment on assignments or examinations. Therefore, the administrator issue could be a challenge from the students' perspective as it is related to their assessment. The assessment uses various online assessment methods to ascertain the amount of in-depth knowledge the students have. The assessment issue has been discussed in previous studies. Most lecturers have indicated the importance and convenience of receiving assignments and providing feedback to students regarding the e-learning platform [35]. This means that academic staff perceive the e-learning system as a platform that facilitates students when submitting assignments and for them to act as teachers providing feedback to learners. Hence, with this convenient platform, there is a need for a conducive interaction between students and lecturers.

\section{Social interactions}

Social interactions are related to how lecturers and students communicate and the challenges they face since online learning limits communication. Communication can still occur between lecturers and students; however, this could become disruptive with any vague or obscure kind of communication. Most of the 18 students believe that face-to-face communication is important for improving understanding. They also raised the issue of limited communication, which could impact the important features of the learning process [8]. Some of the excerpts of the interview are as follows.

As a student, I would say online classes are definitely something new and challenging to me. It is not similar to how we learn in class and can communicate directly with lecturers (UN17)

Online learning might affect my studies since I love to interact directly, just like in the classroom where we can talk and give our opinions during a class session (UN18).

In these crucial times, there is a lack of communication with my lecturers and also my friends, which has an impact on my studies (UN20).

The challenge is that online learning limits my discussions with classmates and teachers (UU5).

It's ineffective on students because it is difficult for students to clear up the misunderstanding when the lecturer is teaching live as well as for them to seek answers (UIT32).

Online learning is difficult for me as I am in year 4 and most of my career marks are based on group presentations, which face-to-face discussions with each other (UIT28).

Together with the medium of online learning, the type of course also impacts the importance of communication and interaction between lecturers and students. This ensures an understanding of the technicalities of preparing a financial statement, such as students from the accountancy course.

In my course, which is accounting, there is a need for a whiteboard that acts as a learning tool or any large space. This is because we learn about financial statements that require us to prepare a long-formatted calculation (M16).

As I'm an accounting student, I would strongly suggest that online learning is really not suitable for my course as I cannot pose any questions to my lecturer directly and I feel that online learning is like lecturers who are just teaching (M11).

Therefore, limited communication between students in this study indicates that it is a challenge to take part in online learning. Few lecturers expressed concern about limited interaction with students in an environment where they never meet the students face-to-face $[13,36]$. In addition, the greatest challenge was the social interaction barrier when it comes to voluntarily take an online course [17]; hence, there is a need to overcome the lack of social interaction during online courses as it is a major contributor to online learning problems. There is a need to have both types of communication [9, 37], whereby the ability of lecturers and students to communicate effectively enhances 
students' emotional intelligence. [28] and [45] also raised the need to maintain a good level of interaction between lecturers and students during online learning in order to avoid miscommunication and improve students' level of satisfaction $[7,11]$.

\section{Technical, connection and data issues}

These issues were commonly discussed by respondents in this study. Most students had raised issues regarding unstable Internet connection, lack of devices and insufficient data, which were challenges to the online learning process during the COVID-19 Pandemic. A stable Internet connection and sufficient data are considered important elements since 66 students had raised these common issues. For example, the issue related to Internet connection required for joining online classes, examinations and assessments. This issue was raised during the interview session.

Online learning is not effective due to the poor Internet connection. To get better quality online learning classes, all persons must have a good internet connection (M4).

Those who do not have a strong data connection or lack technology will be significantly left out from the syllabus (M16).

A weak internet connection can affect how quickly you can connect and participate in a class (M21).

This issue also causes disruptions, as mentioned in the interview.

Using Google online class could be an issue due to a lack of internet access (P2).

We should consider the current situation where everybody is at home and we do not live in the same part of the house. There are people who share rooms and hotspots with their families. Spending extra money just for the internet will be a burden, especially during this RMO. Internet coverage itself sometimes does not help either (UIT2).

This is also a challenge during the assessment according to the excerpts below.

My challenge is when there is a disruption to internet access. Once, I wanted to participate in an online quiz but then I could not access the internet. I got stuck and, in the end, I did not manage to finish my quiz as the time was up already. In addition, I once wanted to upload and send my assignment, but the Internet coverage was not good, so it took some time to upload and sometimes it failed, which made me frustrated (UIT26).

Internet disconnection or slow data transfer might occur causing students to take a long time to finish their work, so it's worthless because the MCO is ongoing and more people are using the Internet, which means a higher bandwidth usage causing too much traffic and creating a lag, so it is not good right now (UIT32).

In order to ensure the continued use of online learning, the technical issue of unstable data connection is considered important. This issue was raised by several students.

The availability of an internet connection for students should be a top priority before pursuing online classes (UM8).

Internet access is the most important element when considering online learning (UM9).

Unclear messages among tutors and students as well as bad internet connection are the biggest disadvantages of online learning (UMS1).

A more stable Wi-Fi connection is needed for implementing online classes (UMS3).

Online learning is good, but students may not receive any additional knowledge and sometimes, if too many students log into the server at the same time, the server will lag and will not be able to load (UMS13). Internet is unstable sometimes, which makes it difficult to access the online learning platform (US1). As for online examinations, power and network disruption might occur and concise information on this matter should be delivered to all parties so that no one faces any problems (US3).

Ifeel a bit demotivated since my internet connection is quite slow in my hometown during this RMO time whereby I could not easily access the e-learning platform (US5).

The challenge I will face if the university still insists on using online learning is that I might be left behind as I do not have a strong Internet connection in my home (UU1).

Need to consider what time students have a stable internet connection so that they can attend online classes using WebEx or zoom (UU4).

As I am a student, I also get affected by this COVID-19 pandemic. Virtual learning is quite challenging for me because it is not as effective as learning in the classroom. It could be because of the internet connection or maybe the student cannot concentrate properly (UN8).

Due to the government's implementation of the MCO, we, as students, are facing the difficulty of learning and finishing our syllabus due to online classes. This is because some of us have problems with the Internet connection (UN5).

Online classes are a hassle for me as I lack Internet access and an out-dated laptop, thus, this makes it difficult to learn online (UN2).

A poor internet connection and some technical problems have a big impact on online class participation (UN3).

Limited connection leads to issues related to insufficient data and outdated devices used. 
I have very limited access to internet quota (UM3). Internet usage will finish very fast and sometimes the internet or Wi-Fi is unstable (UMS9).

Insufficient Internet data (UN7).

Internet access is unstable as some of us are using mobile data instead of Wi-Fi at home (US1).

During this COVID-19 Pandemic, limited and incompatible devices also affect online learning. This issue was raised by several students.

The latest applications might not be compatible with any old version device that some students are using (UIT2).

There are people who lack technology regarding online classes, like video conferencing (UIT18).

It is quite difficult because I do not have a laptop to do my work (UIT35).

Online learning is an inefficient tool for students who live in rural areas because of the lack of Internet facilities (UM1).

The most demanding challenge that I have ever faced while trying to use the online learning platform was my slow device because of its older version of technology. Not all students can afford to buy a good and high spec laptop or any device in order to go online (UU6).

I have a very poor-quality laptop; thus, this makes it difficult to learn online (UN17).

I did not bring my laptop when I came home because of this MCO. So, I am using my sister's laptop to do assignments. If she already has some laptop work, it will be difficult for me to do assignments in the laptop (UN19).

This study shows that the challenge is to ensure students use online learning. The findings of this study are consistent with a study that found limited connectivity does contribute to the challenge of implementing a good e-learning program [38]. Several elements that make e-learning more effective, such as availability of the Internet and faster Internet connectivity/improved bandwidth have also been identified [35, 39]. Strong network coverage is the main factor that influences students' involvement in e-learning and students require a high speed and stable Internet connection [35, 40].

\section{Time and support for studies}

Time and support required for adopting online learning during the COVID-19 Pandemic is also one of the issues raised by students. During this pandemic, students spend time on online learning while neglecting time for themselves. This study identified two issues, namely how students allocate time to meet lecturers' expectations and the ability to manage time in order to participate in online learning. Besides time, there is a need for support from lecturers to ensure that students are motivated to participate in online learning.
Several students had given their take on the support that they need.

It is advisable to implement online learning considering the current situation but a user's manual about its implementation and procedures should be given to students so they would know how to access it (UZ2).

As for online learning, please post all necessary information for students to refer to since we cannot meet our lecturers now for a consultation (UU4).

Together with the support, time spent on online learning is an important element that should be considered by students and lecturers.

It is easy because they can join the class wherever they are (M10).

We also did an online class session through Google Classroom where the instructions were given through the app and through WhatsApp with a sufficient amount of time limit, which was much easier to handle (UIT4).

In my opinion, implementing Online Learning saves time (UMS26).

As mentioned in the excerpts below, it is a challenge to practice proper time management.

I always need to check my email, Microsoft Teams, the WhatsApp group and so on to stay alert about the lecturer's updates (UN17)

Online classes are not effective as it requires more time than face-to-face learning (UN19).

Time could be important in order to complete assignments and assessments.

The way that I am affected during this pandemic is that I'm not able to submit my assignments on time due to a bad Internet connection at home (UN20)

Based on students' feedback, time management is also a challenge.

Lecturers are not following the actual timetable. Thus, it disrupts my personal time (M16).

Online class requires the lecture to monitor students, make a suitable time before class and make early announcements (UIT17).

The time to start online learning is inappropriate (UMS18).

Group discussions take a lot of time (UNI1), which disrupts my personal time (UN10).

I tend to procrastinate on tasks given as I think there is always plenty of time and then, ending up struggling to finish it within a limited period (UN18).

The issue raised by students might relate to how students manage their time efficiently and are able to follow their lecturers' instructions. At the early stage of online learning, most students face the challenge of time management when allocating time for learning and assessments. Students who 
use more effective learning strategies are more skilled in time management; thus, they are expected to be less likely to encounter problems related to lack of time [41]. Time has also been identified as a perceived barrier to students' commitment to online learning and the interruptions that may affect a student's learning [17].

\section{Learner's motivation}

Students' level of motivation is one of the issues that could influence their decision to continue using online learning in the future. This issue is related to how students are motivated to pursue online learning implemented during the COVID-19 Pandemic. Students' motivation can also affect preferences and intentions to further pursue online learning. However, these challenges can arise among students with limited motivation.

When you are not surrounded by classmates and lecturers in a physical setting, it may be tempting to procrastinate on doing assignments and tutorials. But I will always be aware and ready for any future matters (M21).

As for me, using online learning depends on the student. If they do not focus on the discussion or just take it for granted, definitely they will feel it is difficult to understand the discussion. The motivation must come from students themselves (UMS25).

It is important to have up-to-date equipment to motive the use of online learning, as mentioned by some students.

Imagine having a laptop but there is lagging and problems with network connections. It will cause your motivation to deteriorate. It happened to me when I was trying to learn something online (US12).

As for me, my study was affected the most because at home, I have less interest and less effective toward my study (UN20).

Less motivating compared to face-to-face lessons. Loss of concentration is something the student will face (UIT39).

Besides the technical challenges, students' attitude indicates the motivation to use online learning.

Will do all my best even if it is very difficult for me (M3).

Well, it is truly good for me because it helps me to learn again (M8).

Usually, during my online class, the lecturer will ask us to watch a video and then answer the questions given.

Basically, I never had class online using the apps stated before this (UM12).

It motivates me to figure out how to use the new online learning platform which I find interesting (UMS9).

My motivation for online learning is high because it helps me gain more experience (UMS11).

Online learning could still be a good way of learning. Support it (US9).
So far, I do not have any experience in online learning. But I will accept it as it is a good thing to keep trying new learning platforms to improve students' academic performance (UU2).

As for me, it was quite difficult to keep up with the online class at the beginning, but I am getting better at adapting to online learning. It is best to try to keep up with the learning process rather than looking at the bad side because I understand everyone is struggling and trying their best during this situation. I am also thankful for my friends and lecturers who keep helping me during this online class sessions. Sometimes it takes a longer time to finish the tasks because I keep losing my focus (UN20).

Regarding the trying attitude, there are students who lack enthusiasm for online learning.

I am really upset with this kind of learning method, which I find useless and when I think that I'm paying a lot for things that do not work well for me, I feel very unhappy about it (M11).

I really felt uncomfortable with video conferencing type of studies. Seriously (UMS2).

Online learning makes me feel intimidated. Normally, my friends and I have group discussions. It is easier for me to understand when we are discussing face-to-face (US13).

What I fear is that I cannot submit my answer in time when too many people are accessing the online teaching medium in my university because the server will crash (UT2).

This study found that motivation is related to how students anticipate the use of online learning. However, the issue is part of the challenge of limited motivation among students using online learning. The main reason for resistance to using online learning is the low-level of motivation towards any change [10, 42]. Meanwhile, motivation was identified to arise due to the expectation of rewards as well as interest and enjoyment to continue participating in online learning [43, 44]. Studies have also found a positive attitude towards the intention to use online learning could lead to satisfaction $[5,45]$.

\section{Learner's preferences and intention}

Together with motivation, students' preferences and intentions encourage them to use online learning in the future. In order to continue with the preferences and intentions, lecturers must ensure that students enhance their motivation. Twenty six students had raised the issue of limited preferences and intentions to use online learning.

I am open to online learning, but the learning tool used is not suitable for my course (M16).

I think online learning is not suitable because most of my family members are not aware of the online lecture method. They prefer that I do not participate in online learning as they think I just wasting my time (M20). 
I learn better in the classroom or personal study sessions compared to online classes because I do not understand at all what the lecturer is saying (M22). I hope people can consider these things rather than just assume that everyone will just agree to participate in online classes because they have social media, which is a privilege (UIT2).

I prefer face to face teaching. The information given is much clearer than online learning (UIT3).

Online learning is not as effective as physical learning, especially courses that involve calculation/studio (UIT7).

It will create a one-way learning process and will be difficult for the students, I strongly opposed online learning (UIT22).

I find it difficult to take notes while following online classes. I prefer face-to-face learning, but I still can follow online learning if that is the only option (UIT10).

I hope I can study like the previous semester, in the classroom with my friends around me doing assignments and discussing together (UM11).

I prefer face-to-face classes compared to online learning classes (UMS31).

I prefer to study face-to-face rather than go online because the face-to-face method for me is easy to understand and directly capture in mind because the lecturer explains in more understandable terms (UU3).

Based on the issues raised above, there are limited preferences and intentions among students, which poses a challenge to online learning since this change could occur if one has experience. During this COVID-19 Pandemic, students need to use any type of online learning. Students seem to prefer using any type of technology in their study compared to the pen and paper method, while the online learning method is gaining importance in the field of higher education [11].

\section{Learners' understanding}

In order to ensure the efficiency and effectiveness of online learning, there is a need to ensure students understand the learning content during classroom sessions and discussions. This was the issue raised by 28 students, namely the lack of understanding of online learning content that they were taught during the COVID-19 Pandemic. This understanding is important for ensuring the improvement of motivation, preferences, and intentions.

I think subjects related to accounting and calculations are not suitable for this online learning. Whenever I do not understand something, it is difficult for me to ask my lecturer and to understand it well (M19).

As an accounting student, we need to know how to calculate. We need to understand the concept. In some cases, for our subject, it is hard to study using the online study method (UIT14).
The challenge of online learning is that the person does not understanding what online learning is. It is a challenge for the person involved in the online learning program (UIT19).

It is really difficult for me to understand the topic being taught through the online learning method (UIT27).

By using online learning, we cannot get any experience, for example, from the lecturer. I am a person who loves to hear some real examples that are related with our subject and will improve our understanding of the topic (UMS7).

Overall, I do not like to participate in eLearning because I cannot focus on what the lecturer is talking about (UNIS1).

It depends on the course. If the course is more towards calculation and high language use, it is not suitable because it must be shown to me one-by-one and explain why it is like that. If the subject is more on theory, it is suitable because it does not need much technical explanation about something (UZ4).

Online learning seems difficult, especially for accounting students. We need to do some technical work. Sometimes we do not understand what they are teaching through online learning. It is difficult to understand (UN1).

I will not be as comfortable as how we learn in the classroom. Most important, not everyone can attend these online learning classes. Sometimes we don't really understand (UN5).

I think online classes are not effective as we students do not understand much of what the lecturers are teaching. I prefer face-to-face learning for the student to understand better (UN9).

I prefer to study face to face rather than online because the face to face method for me makes it easier for me to understand the subject and directly capture the information in my in mind because the lecturer explains in understandable terms (UU3).

The positive effects of being focused and better understanding the subject matter in virtual learning would be difficult for me because it will be less effective compared to face-to-face learning (UN17).

From the issues adduced above, the lack of understanding among students is a challenge to them at the early stages of using online learning. This is important to ensure that students gain in-depth knowledge about the subject matter. This lack of understanding can be a challenge to most students since they face limited social interaction and motivation during online learning. This was also discussed by previous studies, whereby communication between students and lecturers is important when delivering knowledge to ensure a better understanding during the session. Satisfaction depends on how lecturers deliver knowledge content, appropriateness of knowledge, clarification of misunderstandings and 
increase students' motivation [30]. In addition, sufficient and high-quality knowledge is important for improving the intention to use online learning [10].

\section{Conclusions}

Based on the issues discussed above, this study found seven challenges that might limit students' intention to use online learning. The challenges outlined are the administrator's assessment, communication issues that limit social interaction during an online learning session, technical issues, lack of Internet connection and insufficient data capacity. In addition, other issues raised were the lack of motivation, preferences, intention and students' level of understanding about online learning. Suggestions by previous studies about online learning challenges, lecturers as administrators and also the universities involved, will provide insights on how to improve online learning in future, particularly the implementation of strategies. Strategies must be further developed because it can motivate students and help them continually use the online learning platform [7]. In addition, this current study has contributed to the understanding of challenges on online learning that could indirectly contribute to the future development of strategies on online learning.

Based on the challenges discussed in this study, universities should improve online assessment methods based on the time allocated to lecturers. Besides that, there is a need to ensure a suitable medium for online learning, such as Microsoft Team, GoogleMeet and Zoom, that is provided by universities and effectively used by both lecturers and students. Since there is limited interaction between lecturers and students during online learning, hence, online meetings should be conducted so that students can discuss course matters to develop a better understanding of the subject. Students should be given simple assignments so that they meet the expectations of remote learning. In addition, limitations in the form of technical issues, lack of Internet connection and insufficient data are common challenges related to online learning conducted outside the university campus. These limitations can be overcome by allowing students to continue their studies in universities. This also includes students who have to submit recorded video presentations but face similar limitations. Besides the technical challenges, students need support from their universities in order to sustain their motivation to learn online by using various online platforms. In addition, challenges raised in this study could be related to learners' motivation, preferences, intentions, and understanding. Overall, the challenges can be overcome by improving the online learning method, such as flipped classroom and the learning management system (LMS). This is required if universities wish to sustain the high quality of content development through LMS instead of only being concerned with technological matters. Universities should address the question of online assessment and examinations in order to maintain high accountability and quality of graduates. The Ministry of Higher Education had instructed certain categories of students to return to campus, such as research mode postgraduate students as well as certificate, diploma, final year degree and final semester students whose work require special equipment, final semester and final year students with an unconducive home environment or without Internet access, special needs students in technical, vocational, education and training (TVET) courses at polytechnics and community colleges who need face-to-face teaching and learning and new students for the 2020/2021 academic year. The government could also assist universities and students by providing electronic devices for those unable to purchase them for the purpose of online learning.

Numerous recommendations adduced by this study can be applied in future studies such as focusing specifically on different programs offered by the university with lecturers playing the role of administrators of online learning programs. The target population should include university lecturers who intend to carry out in-depth studies on online learning satisfaction. This is because lecturers' opinions are important when understanding the major players in this context, namely the students and lecturers themselves. In addition, future studies should focus on specific online leaning mediums, such as LMS, Microsoft Team, Microsoft Team, GoogleMeet and Zoom, as well as flipped classroom sessions in order to investigate students' experience and overcome challenges faced during online learning.

\section{Acknowledgments}

We wish to thank the Universiti Tenaga Nasional Malaysia for IRMC PUBLICATION FUND (RJO10517919/iRMC/Publication) for their support and funding.

\section{REFERENCES}

[1] Petrosillo, N., Viceconte, G., Ergonul, O., Ippolito, G., \& Petersen, E. (2020). COVID-19, SARS and MERS: are they closely related?. Clinical Microbiology and Infection. 26(6), 729-734

[2] Rahman, D. (2020). A reckoning for online learning in times of crisis. Available at: https://www.thestar.com.my/opinion/ columnists/whats-your-status/2020/03/24/a-reckoning-for-o nline-learning-in-times-of-crisis

[3] Kamarudin, K. (2020). 'Not All Students Can Benefit From Online Teaching'. Available at: https://www.bernama.com/ 
en/features/news.php?id=1827297

[4] Sani, R. (2020). Making the switch to online learning. Available at: https://www.nst.com.my/education/2020/03/5 78431/making-switch-online-learning? fbclid=IwAR3aphY DfA7MepgxN0JRB0PaJSwB6H3OIOXe0tCUfjR0KbYul2 pjO_JFPYM

[5] Zaili, N., Moi, L. Y., Yusof, N. A., Hanfi, M. N., \& Suhaimi, M. H. (2019). The Factors Of Satisfaction On E-Learning Usage Among Universiti Malaysia Kelantan Students. Journal of Information, 4(11), 73-83

[6] Al-Rahmi, W. M., Alias, N., Othman, M. S., Alzahrani, A. I., Alfarraj, O., Saged, A. A., \& Rahman, N. S. A. (2018). Use of e-learning by University students in Malaysian higher educational institutions: A case in Universiti Teknologi Malaysia. IEEE Access, 6, 14268-14276.

[7] Taat, M. S., \& Francis, A. (2020). Factors Influencing the Students' Acceptance of E-Learning at Teacher Education Institute: An Exploratory Study in Malaysia. International Journal of Higher Education, 9(1), 133-141

[8] Anshari, M., Alas, Y., Sabtu, N. P. H., \& Hamid, M. S. A. (2016). Online Learning: trends, issues and challenges in the Big Data Era. Journal of e-Learning and Knowledge Society, 12(1), 121-134

[9] Omar, A., Amir, Z., \& Mohamad, M. (2018). Facilitating Online Learning: Students' Online Discussion Strategies for a Project Work at a Technical University in Malaysia. 3L: Language, Linguistics, Literature, 24(4), 103-116

[10] Panigrahi, R., Srivastava, P. R., \& Sharma, D. (2018). Online learning: Adoption, continuance, and learning outcome-A review of literature. International Journal of Information Management, 43, 1-14

[11] Mokhtar, S. M., Adnan, N. A. A., Shazali, N. M., \& Ahmad, N. (2020). Why are students involved in e-learning? A reasoning study at Universiti Kebangsaan Malaysia, International Journal of Education and Pedagogy, 2(1), 152-159.

[12] Ghazali, N. B., \& Nordin, M. S. (2018). The perception of university lecturers of teaching and learning in massive open online courses (MOOCs). Journal of Personalized Learning, 2(1), 52-57.

[13] Bolliger, D. U., \& Wasilik, O. (2009). Factors influencing faculty satisfaction with online teaching and learning in higher education. Distance education, 30(1), 103-116.

[14] Appana, S. (2008). A review of benefits and limitations of online learning in the context of the student, the instructor and the tenured faculty. International Journal on E-learning, $7(1), 5-22$.

[15] Ajis, A. F. M., Jali, J. M., Mazlan, M. A., Nordin, S. K., \& Kamal, J. I. A. (2017). Assessing Virtual Learning Environment in Malaysia's Public University. Library Philosophy and Practice.

[16] Vaidyanathan, G. (2018). The adoption of virtual learning environment in blended classes: An empirical study. Issues in Information Systems, 19(4), 69-76

[17] Muilenburg, L. Y., \& Berge, Z. L. (2005). Student barriers to online learning: A factor analytic study. Distance education, 26(1), 29-48
[18] Ghani, E.K; Said, J \& Muhammad, K (2012), The effect of teaching format, students' ability and cognitive effort on accounting students' performance, International Journal of Learning and Development, 2(3), 81-98

[19] Liaw, S.-S. (2008). Investigating students' perceived satisfaction, behavioral intention, and effectiveness of e-learning: A case study of the Blackboard system. Computers \& Education, 51(2), 864-873.

[20] Lin, Y., Lin, G., \& Laffey, J.M. (2008). Building a social and motivational framework for understanding satisfaction in online learning. Journal of Educational Computing Research, $38(1), 1-27$.

[21] Shao, C. (2020, January). An Empirical Study on the Identification of Driving Factors of Satisfaction with Online Learning Based on TAM. In 5th International Conference on Economics, Management, Law and Education (EMLE 2019), 1067-1073.

[22] Aldholay, A. H., Abdullah, Z., Ramayah, T., Isaac, O., \& Mutahar, A. M. (2018). Online learning usage and performance among students within public universities in Yemen. International Journal of Services and Standards, 12(2), 163-179.

[23] Allen, I.E., \& Seaman, J. (2007, October). Online nation: Five years of growth in online learning. Needham, MA: Sloan-C. Retrieved December 28, 2008, from http://www.sloanconsortium.org/publications/survey/pdf/on line_nation.pdf

[24] Navarro, P. (2000). The promise - and potential pitfalls - of cyberlearning. In R.A. Cole (Ed.), Issues in web-based pedagogy: A critical primer (pp. 281-297). Westport, CT: Greenwood Press

[25] Simonson, M., Smaldino, S., Albright, M., \& Zvacek, S. (2009). Teaching and learning at a distance: Foundations of distance education (4th ed.). Boston: Allyn \& Bacon

[26] Rasheed, R. A., Kamsin, A., \& Abdullah, N. A. (2020). Challenges in the online component of blended learning: A systematic review. Computers \& Education, 144, 103701.

[27] Muhammad Sukri Saud, Mohd Anuar Abdul Rahman, \& Ting, K. S. (2007). Studies on the use of e-learning among technical and vocational education students in higher education institutions of Johor. 1st International Malaysian Educational Technology Convention, UTM Skudai, Johor.

[28] Delone, W. H., \& McLean. E. R. (2003). The Delone and McLean Model of information systems success: A Ten-Year update. Journal of Management Information System, 19, 9-30.

[29] Marshal, S. (2014). e-Learningmaturity model. Retrieved September 28, 2016, from http://www.utdc.vuw.ac.nz/resea $\mathrm{rch} / \mathrm{emm} /$

[30] Bhuasiri, W., Xaymoungkhoun, O., Zo, H., Jeung, J., \& Ciganek, A. P. (2012). Computers \& Education Critical success factors for e-learning in developing countries: A comparative analysis between ICT experts and faculty. Computers \& Education, 58(2), 843-855.

[31] Ong, C., Lai, J. \& Wang, Y. (2004). Factors affecting engineers' acceptance of asynchronous e-learning system in high-tech companies. Information and Management, 41, 
795-804.

[32] El-Masri, M., \& Tarhini, A. (2017). Factors affecting the adoption of e-learning systems in Qatar and USA: Extending the Unified Theory of Acceptance and Use of Technology 2 (UTAUT2). Educational Technology Research and Development, 65(3), 743-763.

[33] Liu, I. F., Chen, M. C., Sun, Y. S., Wible, D. \& Kuo, C. (2010). Extending the TAM model to explore the factors that affect Intention to Use an Online Learning Community. Computers and Education, 54, 600-610

[34] Persico, D., Manca, S. \& Pozzi, F. (2014). Adapting the Technology Acceptance Model to evaluate the innovative potential of e-learning systems. Computers in Human Behavior, 30, 614-622

[35] Moakofhi, M., Leteane, O., Phiri, T., Pholele, T., \& Sebalatlheng, P. (2017). Challenges of introducing e-learning at Botswana University of Agriculture and Natural Resources: Lecturers' perspective. International Journal of Education and Development using ICT, 13(2), 4-20

[36] Bower, B.L. (2001). Distance education: Facing the faculty challenge. Online Journal of Distance Learning Administration, 4(2). Retrieved January 1, 2009, from http:// www.westga.edu/ distance/ojdla/summer42/bower42.html

[37] Mohamad, M., Mokhtar, M., Yahaya, M.F. \& Rawian, R.M. (2017). Emotional Intelligence. In Faizah Abdul Majid, Ainul Azmin Md Zamin \& Mohd Fauzi Kamarudin (Eds.). Toolkits for 21st century teaching: Practical implications for the 4th Industry Skills Development. Shah Alam UITM Press, 67-78.
[38] Njaya, T., \& Murangwa, S. I. (2017). An Exploration of the Factors Affecting Learner Satisfaction with Elearning at the Zimbabwe Open University. International Journal of Law, Humanities \& Social Science, 1(6), 37-59

[39] Jethro, O. O., Grace, A. M., \& Thomas, A. K. 2012. E-Learning and its effects on teaching and learning in a global age. International Journal of Academic Research in Business and Social Sciences, 2(1), 203-213

[40] Fook, C. Y., Abd Razak, A., Alias, N. F., \& Narasuman, S. (2017). Students' Readiness and Competence in MOOCs in Higher Education: A Case Study . Man In India , 97(24), 93-101

[41] Henderikx, M., Kreijns, K., Castaño Muñoz, J., \& Kalz, M. (2019). Factors influencing the pursuit of personal learning goals in MOOCs. Distance Education, 40(2), 187-204.

[42] Ali, M., Zhou, L., Miller, L., \& Ieromonachou, P. (2016). User resistance in IT: A literature review. International Journal of Information Management, 36(1), 35-43.

[43] Sun, P. C., Tsai, R. J., Finger, G., Chen, Y. Y., \& Yeh, D. (2008). What drives a successful e-Learning? An empirical investigation of the critical factors influencing learner satisfaction. Computers and Education 50, 1183-1202.

[44] Wang, W. T., \& Hou, Y. P. (2015). Motivations of employees' knowledge sharing behaviors: A self-determination perspective. Information and Organization, 25(1), 1-26.

[45] Kenan, T. (2015). E-Learning Implementation in The School of Engineering At Tripoli. A thesis submitted to the University of Huddersfield in partial fulfillment of the requirements for the degree of Doctor of Philosophy the University of Huddersfield. 